\title{
Mixed infection of Leishmania infantum and Leishmania braziliensis in rodents from endemic urban area of the New World
}

\author{
Eduardo de Castro Ferreira ${ }^{* *}$, Israel Cruz ${ }^{2}$, Carmen Cañavate ${ }^{2}$, Lutiana Amaral de Melo ${ }^{3}$, Agnes Antônia Sampaio Pereira ${ }^{7}$, \\ Filipe A M Madeira ${ }^{4}$, Sofia Alves Nogueira Valério ${ }^{5}$, Heitor Morais Cunha ${ }^{4}$, Adriano Pereira Paglia ${ }^{6}$ \\ and Célia Maria Ferreira Gontijo ${ }^{7}$
}

\begin{abstract}
Background: In Brazil Leishmania braziliensis and L. infantum are the principal species responsible for cutaneous and visceral leishmaniases, respectively. Domestic dogs are the main reservoirs of visceral leishmaniasis, while rodents and marsupials are the main reservoirs for cutaneous leishmaniasis. It has also been suggested that dogs could play a role in transmission of cutaneous leishmaniasis. The identification of the species of Leishmania, the reservoirs, and the vectors involved in each particular transmission cycle is critical for the establishment of control activities. Belo Horizonte has emerged as an endemic region for leishmaniases, however, epidemiological studies assessing the contribution of wild reservoirs to transmission are scarce in the area. The aim of this study was to investigate Leishmania spp. infection in possible reservoirs of an urbanized area.

Results: A high rate of infection was found in small mammals (64.9\%) and dogs (DG1 30.4\% and DG2 48.6\%). The presence of $L$. infantum and L. braziliensis was detected in small mammals and dogs, and mixed infections by both species were detected in rodents which, to the best of our knowledge, is the first description of this phenomenon in an urban area. Additionally, L. amazonensis was detected in the canine samples.

Conclusion: The possible role of these animals as a source of infection of the vector of each species of Leishmania identified should not be overlooked and should be taken into account in future control activities. The results of mixed infection by L. braziliensis and L. infantum in cosmopolitan rodents as M. musculus and R. rattus, may have important implications in the context of the control of leishmaniasis in urban areas, especially when considering that these rodents live in close relationship with human dwellings, especially those in more precarious conditions.
\end{abstract}

Keywords: Leishmania, Hosts, Reservoir, Small mammals, Dogs, Mixed-infections

\section{Background}

The epidemiology of leishmaniases in the New World $(\mathrm{NW})$ is very complex due to the participation of several species of Leishmania, phlebotomine vectors and mammalian hosts. NW visceral leshmaniasis (VL) is endemic or sporadic and is caused by Leishmania (Leishmania) infantum (syn. L. (L.) chagasi). Children under 10 years of age are the main affected population, but adults can also be frequently affected in foci of recent introductions.

\footnotetext{
* Correspondence: ecferreira@fiocruz.br

${ }^{1}$ Fiocruz Mato Grosso do Sul, Fundação Oswaldo Cruz, Campo Grande, MS, Brasil

Full list of author information is available at the end of the article
}

Several phylogenetically distinct species of Leishmania are responsible for the forms of cutaneous leishmaniasis (CL), from localized cutaneous lesions to the destructive mucosal affliction [1].

Cutaneous leishmaniasis is widespread in Brazil, which accounts for most CL cases in South America with an estimated average incidence of 100.5 cases per 100,000 inhabitants. Until the 1950s most of the cases of CL in Brazil were concentrated in the states of São Paulo, Paraná, Minas Gerais, Ceará and Pernambuco, and associated with deforestation and new human settlements. Due to the expansion of these activities the disease has spread to many other areas, including the municipality 
of Belo Horizonte, the capital of the state of Minas Gerais [2]. VL is also a serious public health problem in Brazil, with escalating incidence $(1.85 / 100,000$ inhabitants) and broadening geographical extension; northeastern states are particularly affected. Currently, VL is strongly linked to urban settlements in Brazil, where human made changes as well as adaptive changes in the behavior of reservoirs and vectors contribute to its prevalence. Thus, since 1980 several urban VL epidemics have taken place in Brazilian cities, including Belo Horizonte $[3,4]$.

Several domestic, synanthropic, and wild animals have been found infected by different species of Leishmania in urban areas, thus the identification of sources of infection and the epidemiology of each clinical form of leishmaniasis becomes a complex matter [1,5-11]. Throughout the last decade, the detection of leishmanial DNA has been shown to be a useful approach in detecting Leishmania infection in dogs and other mammals in urban and sylvatic environments in Brazil, and particularly in the state of Minas Gerais [12-18].

Both CL and VL have been known to be endemic in Belo Horizonte for a long time $[19,20]$. This is a heavily urbanized and densely inhabited area, where transmission of leishmaniases occurs in practically all quarters of the city, resembling an urban transmission pattern already described $[2,3,21,22]$.

In this study we aimed to use nested polymerase chain reaction (PCR) to target the SSUrRNA gene [23] in order to assess the presence of Leishmania infection in peripheral blood and different tissues obtained from dogs and small mammals from the Municipality of Belo Horizonte. The PCR method used has been validated and applied in previous studies assessing Leishmania infection in both humans and dogs $[24,25]$. In combination with DNA sequencing of positive PCR products we attempted to identify the Leishmania species complexes infecting the study animals. We believe that studies such as ours will contribute to an improved understanding of the epidemiology of the leishmaniases and will help to establish further control activities.

\section{Methods}

\section{Study location}

The study was performed from November 2007 to March 2008 in the Municipality of Belo Horizonte (capital of Minas Gerais State, Brazil). The city is built on several hills, is completely surrounded by mountains, and has several large parks in its immediate surroundings. Belo Horizonte has a global surface area of $331 \mathrm{Km}^{2}$, and is characterized by a subtropical climate with annual precipitation of $1491 \mathrm{~mm}$ and average temperature of $22^{\circ} \mathrm{C}$ $\left(11^{\circ} \mathrm{C}-31^{\circ} \mathrm{C}\right)$. The human population of Belo Horizonte is $2,375,151$ inhabitants [26] and is undergoing intense urbanization.

\section{Study design animals and samples}

The number of samples was defined by estimating the proportion of the population with a confidence level of $95 \%$, precision of 0.1 and prevalence of $50 \%$. This value was estimated without any previous data and considering the prevalence of $50 \%$ gives the largest " $n$ " possible. The calculated $\mathrm{n}$ was 100 , both for dogs and for small mammals.

The project obtained permission from the Ministry of Environment Agency in Brazil, the Brazilian Institute for Environment (IBAMA), for capture and euthanasia of small mammals.

The points of collecting samples of dogs and small mammals in domiciliary and peridomestic areas were chosen considering the presence of human cases of VL and/or LT in the household, or close to it, in the three years preceding the start of research.

The study was based on a sample of 189 animals originating from two sources: i) 97 small mammals (62 rodents and 35 marsupials) captured with Tomahawk traps from peri-domestic habitats (20 houses, each one with two traps) and from forested areas in early succession around different households in Belo Horizonte (three tracks, each containing 15 traps separated by a distance of about 20 meters) (Table 1). The sampling effort, at the end of the six campaigns, was 1200 traps in peridomestic area and 1350 traps in the forested area, adding up to a total of 2550 traps during the period of study ; and ii) 92 domestic dogs (with owners) from the same households from which small mammals were captured (hereinafter dog group-1, DG1).

An additional set of dog samples was included in this study (hereinafter dog group-2, DG2). This group was made up of DNA extracted from peripheral blood, bone marrow and ear skin of 70 dogs obtained in study location during a previous survey [27], to evaluate whether there were changes in the profile of infection in dogs from the same area, in both periods studied, applying the same methodology on samples of the two groups.

Table 1 Number of individuals of small mammal species captured in each habitat between June 2006 to November 2007 in Belo Horizonte, Minas Gerais, Brasil

\begin{tabular}{lllll}
\hline Order & Species & Forest & Peridomestic & Total \\
\hline Rodentia & Mus musculus & 4 & 20 & 24 \\
& Rattus rattus & 8 & 11 & 19 \\
& Rattus norvegicus & 1 & 8 & 9 \\
& Necromys lasiurus* & 5 & 0 & 5 \\
& Cerradomys subflavus* & 5 & 0 & 5 \\
Didelphimorphia & Didelphis albiventris* & 31 & 3 & 34 \\
& Didelphis aurita* & 1 & 0 & 1 \\
& Total & 55 & 42 & 97 \\
\hline
\end{tabular}

*Native species. 
Small mammals were anaesthetized and sacrificed, and then samples from tail skin, ear skin, liver, spleen, and bone marrow were collected. Peripheral blood samples were taken from dogs. Peripheral blood and bone marrow samples were preserved in EDTA tubes at $-20^{\circ}$ $\mathrm{C}$ whereas the other tissue samples were stored in $70 \%$ ethanol at $-20^{\circ} \mathrm{C}$ until analysis.

Informed consent was obtained from each dog owner before sampling. The procedures employed for the collection of clinical material from dogs and small mammals were carried out according to the Ethical Principles in Animal Experimentation and the project was licensed by the Ethics Commission on the Use of Animals/FIOCRUZ under reference number P0119-02.

\section{DNA extraction}

The Genomic Prep Cells and Tissues DNA Isolation Kit ${ }^{\bullet}$ (GE Healthcare) was used for DNA extraction from skin, liver, and spleen samples and the Column Chromatography-GFX Genomic DNA Blood Purification System ${ }^{\circ}$ (GE Healthcare) was used for peripheral blood and bone marrow samples. In both cases the instructions provided by the manufacturer were followed.

\section{Detection of Leishmania DNA}

Detection of Leishmania DNA was done by means of Leishmania nested-PCR (LnPCR) targeting the SSUrRNA gene, as described elsewhere [24]. This protocol is specific to the genus Leishmania and uses the primer pair R221 (5'-GGT TCCTTT CCT GAT TTA CG-3') and R332 (5'GGC CGGTAA AGG CCG AAT AG-3') in the first reaction, and R223 (5'-TCC CAT CGC AAC CTC GGT T-3') and R333 (5'-AAA GCG GGC GCG GTG CTG-3') in the nested reaction. The PCR reagents (Biotools $B \& M$ Labs, SA) and the thermal cycler (GenAmp PCR System 9800, Applied Biosystems) were used following the conditions and the cycling program previously described [24]. Every assay included DNA extraction negative and positive controls and PCR negative and positive controls. The presence of the final specific positive LnPCR product (353 bp) was assessed by $1.5 \%$ agarose gel electrophoresis, ethidium bromide staining and UV visualization. The detection limit observed was equivalent to 1 and 10 parasites/uL in culture samples of reference strains of L. infantum and L. braziliensis, respectively.

\section{DNA sequencing}

For species identification, all LnPCR positive products were excised from the gel and purified using the QIAquick Gel Extraction Kit (QIAGEN) following the protocol provided by the manufacturer. Direct sequencing of the purified LnPCR positive products was performed with forward and reverse primers using the Big-Dye Terminator Cycle Sequencing Ready Reaction Kit V3.1 and the automated ABI PRISM 377 DNA sequencer (Applied Biosystems). Sequences thus obtained were analyzed and edited using Lasergene ${ }^{\bullet}$ sequence analysis software (DNASTAR). The edited sequences were compared with those deposited at GenBank.

\section{Statistical analysis}

The differences of positive frequencies were analyzed by chi-square test $\left(\mathrm{x}^{2}\right)$ and for multiple comparisons was used the Bonferroni method. The level of significance was $5 \%$.

\section{Results}

We captured a total of five species of rodents and two species of marsupials in both habitats (Table 1). Native wild species were captured mostly in forested areas while in the peri-domestic areas all species captured, except the white-eared opossum (Didelphis albiventris), were exotic and synanthropic.

After LnPCR analysis of the different biological samples any animal presenting an LnPCR positive result (Figure 1) in at least one of the biological samples tested was considered infected. Small mammals $(\mathrm{N}=97)$ had the highest infection rate (47.4-83.3\%), which varied according to species (details in Table 2). Among dogs, DG1 $(\mathrm{N}=92)$ showed an infection rate of $30.4 \%$, while DG-2 $(\mathrm{N}=70)$ had an infection rate of $48.6 \%$ (Table 2$)$. Among small mammals, samples from liver, spleen and tail skin showed a higher infection rate (22.4-33.7\%) than samples taken from ear skin and bone marrow (5.2-10.2\%). No significant differences were observed in the infection rate of the different samples taken from DG2 (Table 3).

DNA sequence analysis of the amplified fragment of the SSUrRNA gene indicated that species from the $L$. brazilensis complex were infecting 54\%, 82.1\% and 5.9\% of the LnPCR positive small mammals, DG-1 and DG-2, respectively. Infection by species of the $L$. donovani complex was determined in $12.7 \%, 17.9 \%$ and $82.3 \%$, of the LnPCR positive small mammals, DG1 and DG2, respectively. When different Leishmania species complexes were identified in different biological samples from the same animal the infection was considered

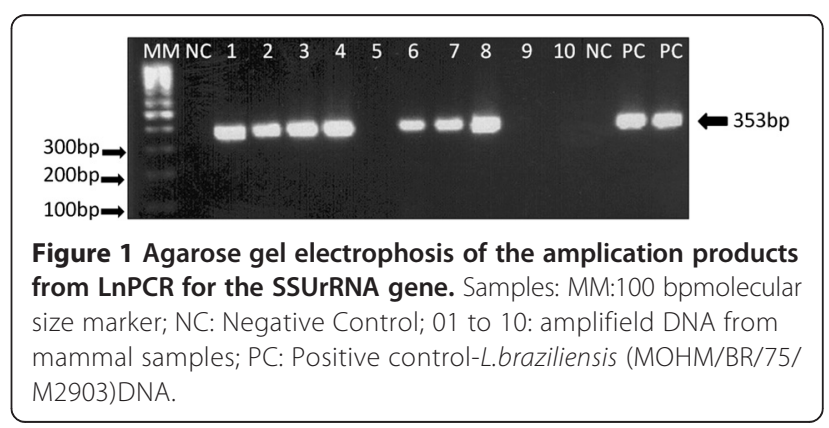


Table 2 Positivity of LnPCR in samples of rodents, marsupials and dogs from Belo Horizonte, Minas Gerais, Brazil

\begin{tabular}{lll}
\hline Host specie & Sample & LnPCR \\
\hline M. musculus & $* *$ & $83.3 \%$ \\
R. rattus & $* *$ & $47.4 \%$ \\
R. norvegicus & $* *$ & $66.7 \%$ \\
N. lasiurus & $* *$ & $60 \%$ \\
C. subflavus & $* *$ & $80 \%$ \\
D. albiventris & $* *$ & $61.8 \%$ \\
D. aurita & $* *$ & $0 \%$ \\
C. familiaris DG1 & Blood & $30.4 \%$ \\
C. familiaris DG2 & $* *$ & $48.6 \%$ \\
\hline
\end{tabular}

**Positivity in at least one evaluated tissue, including blood, ear skin, and bone marrow for $C$. familiaris (2) and ear skin, tail skin, liver, spleen, and bone marrow for the other hosts.

mixed; mixed infection by species of the $L$. donovani complex and L. braziliensis complex were detected in $4.7 \%$ of the LnPCR positive small mammals (two Mus musculus, and one Rattus rattus). Infection by L. amazonensis was observed in $5.9 \%$ of the LnPCR positive dogs of DG2. Due to weak amplification it was not possible to obtain accurate DNA sequences for species complex identification in $28.6 \%$ and $5.9 \%$ of the LnPCR positive small mammals and dogs of DG2, respectively. Details on the species complex identification for each animal species are provided in Table 4.

\section{Discussion}

The present study represents the first time that PCR targeting the SSUrRNA gene and further DNA sequencing has been used in an epidemiological study on samples from both domestic dogs and small mammals. Furthermore, this study adds to the previous work by Marcelino and colleagues [28], who applied the same methodology to confirm infection by the $L$. braziliensis species complex in a sample of Rattus norvegicus. This methodology, however, only allows identification to the level of species complex and further analysis using other DNA targets, such as the $H s p 70$ gene, would be necessary to allow identification to the species level [29].

The present study also identified, for the first time, mixed infection by the $L$. donovani species complex and the $L$. braziliensis species complex in three small mammals (two M. musculus and one $R$. rattus) captured in peri-domestic habitats of three different households of Belo Horizonte. The overlapping of transmission cycles of different species of Leishmania in a given area can lead to the occurrence of mixed infections, as has been observed by other authors [30-33]. This is an astonishing finding since these two species of rodents are commonly found in urban areas close to domestic habitats and in association with inadequate hygiene and environmental disorganization.

In epidemiological studies in areas of occurrence of different species of Leishmania, the collection of biological samples from different tissues increases not only the probability of detecting mixed infections [30], but also the chance of detecting the parasite itself, as shown in Table 3.

Another fact that caught our attention was the presence of domestic dogs infected by Leishmania belonging to the L. mexicana complex. This finding, indicates that sympatric transmission of $L$. amazonensis species of the $L$. braziliensis and $L$. donovani complexes is occurring.

The species of Leishmania most prevalent in small mammals, both in the forested and peri-domestic areas, was $L$. braziliensis followed by $L$. infantum. Although none of the small mammals were found to be infected by $L$. amazonensis, the possibility should not be entirely ruled out since it was not possible to identify the etiologic agent of $29.7 \%$ of the small mammals that were infected. This is especially true if we consider that this species of Leishmania is encountered in dogs [34], and

Table 3 Positivity of Leishmania sp. specific PCRs performed on DNA extracted from different tissues of small mammals and dogs

\begin{tabular}{lllllll}
\hline Host specie & Ear skin & Tail skin & Bone marrow & Liver & Spleen & Blood \\
\hline M. musculus & $12.5 \%$ & $17.4 \%$ & $5 \%$ & $56.5 \%$ & $60.9 \%$ & $\mathrm{NR}$ \\
R. rattus & $15.8 \%$ & $5.3 \%$ & $5.3 \%$ & $0 \%$ & $5.3 \%$ & $\mathrm{NR}$ \\
R. norvegicus & $33.3 \%$ & $33.3 \%$ & $0 \% .5 \%$ & $60 \%$ & $60 \%$ & $\mathrm{NR}$ \\
N. lasiurus & $0 \%$ & $0 \%$ & $20 \%$ & $60 \%$ & $40 \%$ & $\mathrm{NR}$ \\
C. subflavus & $0 \%$ & $0 \%$ & $6.1 \%$ & $14.7 \%$ & $20.6 \%$ & $\mathrm{NR}$ \\
D. albiventris & $3 \%$ & $38.2 \%$ & $0 \%$ & $\mathrm{NR}$ & $\mathrm{NR}$ & $\mathrm{NR}$ \\
D. aurita & $0 \%$ & $\mathrm{~N} \%$ & $\mathrm{NR}$ & $\mathrm{NR}$ & $\mathrm{NR}$ & $31.5 \%$ \\
C. familiaris DG1 & $\mathrm{NR}$ & $\mathrm{NR}$ & $32.9 \%$ & & & $21.4 \%$ \\
C. familiaris DG2 & $25.7 \%$ & $\mathrm{NR}$ & & & &
\end{tabular}

NR_Unrealised. 
Table 4 Identification of Leishmania by the sequencing of the LnPCR product in samples of small mammals and dogs

\begin{tabular}{|c|c|c|c|c|c|c|}
\hline \multirow[t]{2}{*}{ Host species (n) } & \multirow[t]{2}{*}{ Sample } & \multicolumn{5}{|c|}{ Leishmania Complex } \\
\hline & & L.b & L.d & L.b + L.d & L.m & Leishmania sp \\
\hline M. musculus (20) & $* *$ & $55 \%$ & $10 \%$ & $10 \%$ & $0 \%$ & $25 \%$ \\
\hline R. rattus (09) & $* *$ & $44.4 \%$ & $0 \%$ & $11.2 \%$ & $0 \%$ & $44.4 \%$ \\
\hline R. norvegicus (06) & $* *$ & $66.6 \%$ & $16.7 \%$ & $0 \%$ & $0 \%$ & $16.7 \%$ \\
\hline N. lasiurus (03) & $* *$ & $100 \%$ & $0 \%$ & $0 \%$ & $0 \%$ & $0 \%$ \\
\hline C. subflavus (04) & $* *$ & $50 \%$ & $25 \%$ & $0 \%$ & $0 \%$ & $25 \%$ \\
\hline D. albiventris (21) & $* *$ & $47.6 \%$ & $19 \%$ & $0 \%$ & $0 \%$ & $33.4 \%$ \\
\hline C. familiaris DG1 (28) & Blood & $82 \%$ & $18 \%$ & $0 \%$ & $0 \%$ & $0 \%$ \\
\hline C. familiaris DG2 (34) & $* *$ & $5.9 \%$ & $82.3 \%$ & $0 \%$ & $5.9 \%$ & $5.9 \%$ \\
\hline
\end{tabular}

**Identification carried out in at least one positive tissue by the PCR, including ear skin, tail skin, liver, spleen, and bone marrow for the small mammals and blood, ear skin, and bone marrow for DG2. L. b (Leishmania braziliensis), L. d (L. donovani), L.m (L.mexicana).

other authors have reported the detection of infection by this species in small mammals from different regions of Brazil $[14,35,36]$.

The identification of the parasites present in infected dogs and small mammals has revealed species belonging to the Leishmania braziliensis, Leishmania mexicana, and Leishmania donovani complexes. This, combined with the results of Saraiva and colleagues [37] who detected the presence of these species in phlebotomines, confirms the occurrence of an active transmission cycle of these different species in Belo Horizonte.

In captures of sandflies taken during the same period of DG2 samples collection, $68 \%$ of specimens were $L$. longipalpis [38]. Moreover, in a survey conducted in the same area and period that the DG1 and small mammal samples were collected, $75 \%$ of the sandfly specimens captured were L. whitmani [39]. The above mentioned, prevalence of L. infantum in DG2 and L. braziliensis in DG1 and small mammals are understandable given the predominance of the respective vectors in the different periods.

Most of the necessary conditions for incriminating a species as a reservoir of Leishmania [11], was observed in the dogs and small mammals sampled in our study.

Among commensal synanthropic species, the rat ( $R$. norvegicus), the roof rat ( $R$. rattus), and the mouse (M. musculus) are particularly important because they have a cosmopolitan distribution and are responsible for most of the economic losses and health caused to man [40]. The high rates of infection detected in these species, as well as the possibility of harboring different species of Leishmania, coupled with the proliferation of these animals in urban areas suggest the possibility that they are contributing to the maintenance of the transmission cycles of Leishmania sp. Moreover, these synanthropic species were also trapped in the forested areas. Freitas and colleagues [41] also suggest that M. musculus participates in the transmission cycle of L. braziliensis in an endemic area of the state of Mato Grosso, Brazil.
With respect to the white-eared opossum $D$. albiventris, this species showed a high rate of infection in tail skin (38.2\%) with parasites characterized as L. braziliensis or L. infantum, which corroborates the findings of numerous authors $[5,16,18,36,42,43]$. Although most specimens were captured in the forested area, $D$. albiventris has a large home range and highly synanthropic habits, which could make them a link between wild and urban transmission cycles.

The presence of dogs infected with L. braziliensis and L. infantum in a city like Belo Horizonte is consistent with what has been described by other authors in LT and LV endemic areas $[3,44,45]$. In addition, the high percentage of dogs infected by L. braziliensis in an area with LV transmission should be evaluated by other methods, besides the serological diagnosis, to perform euthanasia of seropositive dogs, as recommended by the Ministry of Health of Brazil for LV control [46]; it is known the possibility of cross-reactions by serological tests used in Brazil for diagnosis of dogs infected by L. braziliensis [27].

The present study shows that three different leishmanial entities ( $L$. donovani species complex, L. braziliensis species complex, and L. mexicana species complex) are present as etiological agents in the infection of domestic dogs from the Belo Horizonte, which is considered an endemic area for VL and CL. Additionally, small mammals in peri-domestic and forested areas are also infected by parasites of the L. donovani species complex or the L. braziliensis species complex.

\section{Conclusions}

Mixed infection by $L$. braziliensis and L. infantum in cosmopolitan rodents as $M$. musculus and $R$. rattus, may have important implications in the context of the control of leishmaniasis in urban areas, especially when considering that these rodents live in close relationship with human dwellings, especially those in more precarious conditions. The possible role of these animals as a 
source of infection for the vector of each Leishmania sp. identified in Belo Horizonte should not be overlooked and should be taken into account in future control activities. Furthermore, studies of the hosts of Leishmania spp., the potential reservoirs of these parasites, should be encouraged in several endemic areas of the disease in order to understand the real role of the different host species in the complex eco-epidemiology of leishmaniasis.

\section{Abbreviations}

NW: New World; L.: Leishmania; VL: Visceral leishmaniasis; CL: Cutaneous leishmaniasis; PCR: Polymerase chain reaction; DG1: Dog group 1; DG2: Dog group 2; LnPCR: Leishmania nested PCR.

\section{Competing interests}

The authors declare that they have no competing interests.

\section{Authors' contributions}

CMFG and ECF conceived the study; IC and CC assisted with study design; APP determined the trapping locations for small mammals; ECF, LAM, HMC, FAMM, SANV and APP conducted field sampling; HMC, FAMM and APP performed small mammal species identification; ECF LAM, AASP carried out DNA extraction; ECF, IC and AASP carried out PCR, DNA sequencing, and analyses of sequences thus generated; ECF, CMFG, AASP and IC drafted the manuscript; All authors read and approved the final version of the manuscript.

\section{Acknowledgments}

The authors wish to thank the Fundação de Amparo à Pesquisa do Estado de Minas Gerais (FAPEMIG), the Conselho Nacional de Desenvolvimento Científico e Tecnológico (CNPq), the Coordenação de Aperfeiçoamento de Pessoal de Nível Superior (Capes), the Fundação Oswaldo Cruz (FIOCRUZ) and European Community (EC - LeishEpiNetSA Consortium) for financially supporting the study. We are also grateful to the Centro de Controle de Zoonoses da Prefeitura de Belo Horizonte for assistance and logistic support, and to Zoraida del Carmen Fernandez Grillo for assistance in revising the text in English.

\section{Author details}

${ }^{1}$ Fiocruz Mato Grosso do Sul, Fundação Oswaldo Cruz, Campo Grande, MS, Brasil. ${ }^{2} \mathrm{WHO}$ Collaborating Center for Leishmaniasis, Servicio de Parasitología, Centro Nacional de Microbiología, Instituto de Salud Carlos III, Madri, Espanha. ${ }^{3}$ Serviço de Biologia Molecular e Bioinformática, Diretoria de Pesquisa e Desenvolvimento, Fundação Ezequiel Dias, Belo Horizonte, MG, Brasil. ${ }^{4}$ Sete Soluções e Tecnologias Ambientais, Belo Horizonte, MG, Brasil. ${ }^{5}$ Regional Nordeste, Secretaria de Saúde de Belo Horizonte, Belo Horizonte, MG, Brasil. ${ }^{6}$ Departamento de Biologia Geral, Instituto de Ciências Biológicas, Universidade Federal de Minas Gerais, Belo Horizonte, MG, Brasil. '7 Grupo de Estudos em Leishmanioses, Centro de Pesquisas René Rachou, Fundação Oswaldo Cruz, Belo Horizonte, MG, Brasil.

Received: 27 October 2014 Accepted: 11 March 2015

Published online: 20 March 2015

\section{References}

1. World Health Organization. Control of the leishmaniases, vol. 949. Geneva, Switzerland: WHO Technical Report Series; 2010.

2. Passos VMA, Falcão AL, Marzochi MCA, Gontijo CMF, Dias ES, Barbosa-Santos EGO, et al. Epidemiological aspects of American Cutaneous Leishmaniasis in a periurban area of the metropolitan region of Belo Horizonte, Minas Gerais, Brazil. Mem Inst Oswaldo Cruz. 1993:88:103-10.

3. Silva ES, Gontijo CMF, Pacheco RS, Fiuza VOP, Brazil RP. Visceral leishmaniasis in the metropolitan Region of Belo Horizonte, State of Minas Gerais, Brazil. Mem Inst Oswaldo Cruz. 2001;96:285-91.

4. Costa $\mathrm{CH}$. Characterization and speculations on the urbanization of visceral leishmaniasis in Brazil. Cad Saude Publica. 2008;24:2959-63.
5. Sherlock IA, Miranda JC, Sadigursky M, Grimaldi Jr G. Natural infections of the Didelphis albiventris (Marsupialia, Didelphidae) with Leishmania donovani in Brazil. Mem Inst Oswaldo Cruz. 1984;79:511.

6. Brazil RP, Nascimento MDSB, Macau RP. Infecção natural do porco (Sus scrofa) por Leishmania em foco recente de Leishmaniose Tegumentar na llha de São Luís, Maranhão. Mem Inst Oswaldo Cruz. 1987;82:145.

7. Ashford RW. The leishmaniases as emerging and reemerging zoonoses. Int J Parasitol. 2000;30:1269-81.

8. Brandão-Filho SP, Brito ME, Carvalho FG, Ishikawa EA, Cupolillo E, Floeter-Winter L, et al. Wild and synanthropic hosts of Leishmania (Viannia) braziliensis in the endemic cutaneous leishmaniasis locality of Amaraji, Pernambuco State, Brazil. Trans R Soc Trop Med Hyg. 2003;97:291-6.

9. Mancianti F. Feline leishmaniasis: what's the epidemiological role of the cat? Parassitologia. 2004;46:203-6.

10. da Silva AVM, de Paula AA, Cabrera MAA, Carreira JCA. Leishmaniasis in domestic dogs: epidemiological aspects. Cad Saúde Pública. 2005;21:324-8.

11. Silva ES, Gontijo CMF, Melo MN. Contribution of molecular techniques to the epidemiology of neotropical Leishmania species. Trends Parasitol. 2005;21(12):550-2

12. Silva ES, Gontijo CM, Pirmez C, Fernandes O, Brazil RP. Short report: detection of Leishmania DNA by polymerase chain reaction on blood samples from dogs with visceral leishmaniasis. Am J Trop Med Hyg. 2001:65:896-8.

13. Reithinger R, Quinnell RJ, Alexander B, Davies CR. Rapid detection of Leishmania infantum infection in dogs: comparative study using an immunochromatographic dipstick test, enzyme-linked immunosorbent assay, and PCR. J Clin Microbiol. 2002;40:2352-6.

14. Oliveira FS, Pirmez C, Pires MQ, Brazil RP, Pacheco RS. PCR-based diagnosis for detection of Leishmania in skin and blood of rodents from an endemic area of cutaneous and visceral leishmaniasis in Brazil. Vet Parasitol. 2005;129:219-27.

15. Silva ES, van der Meide WF, Schoone GJ, Gontijo CM, Schallig HD, Brazil RP. Diagnosis of canine leishmaniasis in the endemic area of Belo Horizonte, Minas Gerais, Brazil by parasite, antibody and DNA detection assays. Vet Res Commun. 2006;30:637-43.

16. Schallig HD, da Silva ES, van der Meide WF, Schoone GJ, Gontijo CM Didelphis marsupialis (common opossum): a potential reservoir host for zoonotic leishmaniasis in the metropolitan region of Belo Horizonte (Minas Gerais, Brazil). Vector Borne Zoonotic Dis. 2007;7:387-93.

17. de SA F, Ituassu LT, de Melo MN, de Andrade AS. Evaluation of the conjunctival swab for canine visceral leishmaniasis diagnosis by PCR-hybridization in Minas Gerais State, Brazil. Vet Parasitol. 2008:152:257-63.

18. Quaresma PF, Rêgo FD, Botelho HA, da Silva SR, Moura Júnior AJ, Teixeira Neto RG, et al. Wild, synanthropic and domestic hosts of Leishmania in an endemic area of cutaneous leishmaniasis in Minas Gerais State, Brazil. Trans R Soc Trop Med Hyg. 2011;105:579-85.

19. Genaro O, Costa CA, Williams P, Silva JE, Rocha NM, Lima SL, et al. Ocorrência de calazar em área urbana da Grande Belo Horizonte, MG. Rev Soc Bras Med Trop. 1990;23:121.

20. Passos VMA, Falcão AL, Katz N. Urban american cutaneous leishmaniasis in the metropolitan region of Belo Horizonte, Minas Gerais, Brazil. Mem Inst Oswaldo Cruz. 1990;85:243-4.

21. Luz ZMP, Pimenta DN, Cabral ALV, Fiúza VOP, Rabello A. A urbanização das leishmaniases e a baixa resolutividade diagnóstica em municípios da Região Metropolitana de Belo Horizonte. Rev Soc Bras Med Trop. 2001;34:249-54

22. Margonari C, Freitas CR, Ribeiro RC, Moura ACM, Timbó M, Gripp AH, et al. Epidemiology of visceral leishmaniasis through spatial analysis in Belo Horizonte municipality, State of Minas Gerais, Brazil. Mem Inst Oswaldo Cruz. 2006:101:31-8

23. Cruz I, Cañavate C, Rubio JM, Morales MA, Chicharro C, Laguna F, et al. Spanish HIV-Leishmania Study Group. A nested polymerase chain reaction (Ln-PCR) for diagnosing and monitoring Leishmania infantum infection in patients co-infected with human immunodeficiency virus. Trans R Soc Trop Med Hyg. 2002;96 Suppl 1:S185-9.

24. Cruz I, Chicharro C, Nieto J, Bailo B, Cañavate C, Fiqueras MC, et al. Comparison of new diagnostic tools for management of pediatric Mediterranean visceral leishmaniasis. J Clin Microbiol. 2006;44:2343-7.

25. Cruz I, Acosta L, Gutiérrez MN, Nieto J, Cañavate C, Deschutter J, et al. A canine leishmaniasis pilot survey in an emerging focus of visceral leishmaniasis: Posadas (Misiones, Argentina). BMC Infect Dis. 2010;10:342. 
26. Belo Horizonte [http://cidades.ibge.gov.br/xtras/perfil.php? lang=\&codmun=310620]

27. Ferreira EC, de Lana M, Carneiro M, Reis AB, Paes DV, Silva ES, et al. Comparison of serological assays for the diagnosis of canine visceral leishmaniasis in animals presenting different clinical manifestations. Vet Parasitol. 2007;146:235-41.

28. Marcelino AP, Ferreira EC, Avedanha JS, Costa CF, Chiarelli D, Almeida G, et al. Molecular detection of Leishmania braziliensis in Rattus norvegicus in an area endemic for cutaneous leishmaniasis in Brazil. Vet Parasitol. 2011:183:54-8.

29. Fraga J, Montalvo AM, De Doncker S, Dujardin JC, Van der Auwera G. Phylogeny of Leishmania species based on the heat-shock protein 70 gene. Infect Genet Evol. 2010;10:238-45.

30. Madeira MF, Schubach AO, Schubach TMP, Pacheco RS, Oliveira FS, Pereira SA, et al. Mixed infection with Leishmania (Viannia) braziliensis and Leishmania (Leishmania) chagasi in a naturally infected dog from Rio de Janeiro, Brazil. Trans R Soc Trop Med Hyg. 2006;100:442-5.

31. Martinez E, Mollinedo S, Torrez M, Muñoz M, Bañuls AL, Lê Pont F. Coinfection by Leishmania amazonensis and L. infantum/L. chagasi in a case of diffuse cutaneous leishmaniasis in Bolivia. Trans R Soc Trop Med Hyg. 2002;96:529-32.

32. Oliveira Neto MP, Marzochi MCA, Grimaldi GJ, Pacheco RS, Toledo LM, Momen $\mathrm{H}$. Concurrent human infection with Leishmania donovani and Leishmania braziliensis braziliensis. Ann Trop Med Parasitol. 1986;80:587-92.

33. Silveira FT, Lainson R, Shaw JJ, Ribeiro RSM. Leishmaniose cutânea na Amazônia. Registro do primeiro caso humano de infecção mista, determinado por duas espécies distintas de Leishmanias: Leishmania braziliensis e Leishmania mexicana amazonensis. Rev Inst Med Trop Sao Paulo. 1984;26:272-5.

34. Santos-Dias E, Regina-Silva S, França-Silva JC, Paz GF, Michalsky EM, Araujo SC, et al. Eco-epidemiology of visceral leishmaniasis in the urban area of Paracatu, state of Minas Gerais, Brazil. Vet Parasitol. 2011;176:101-11.

35. Lainson R, Shaw JJ. Leishmaniasis in Brazil: I. Observations on enzootic rodent leishmaniasis - incrimination of Lutzomyia flaviscutellata (Mangabeira) as the vector in the lower Amazonian basin. Trans R Soc Trop Med Hyg. 1968;62(3):385-95.

36. Sherlock A, Miranda JC, Sadigurski M, Grimaldi Jr G. Observações sobre o calazar em Jacobina, Bahia: IV Investigações sobre reservatórios silvestres e comensais. Rev Soc Bras Med Trop. 1988;21:23-7.

37. Saraiva L, Andrade-Filho JD, Silva SO, de Andrade ASR, Melo MN. The molecular detection of different Leishmania species within sand flies from a cutaneous and visceral leishmaniasis sympatric area in Southeastern Brazil. Mem Inst Oswaldo Cruz. 2010;105(8):1033-9.

38. Margonari C, Pessanha JE, Barata RA, Michalsky EM, Costa DC, Santos Dias E. Study on phlebotomine sand fly (Diptera: Psychodidae) Fauna in Belo Horizonte, State of Minas Gerais, Brazil. Mem Inst Oswaldo Cruz. 2004;99(8):795-803.

39. Saraiva L, Andrade Filho JD, Falcão AL, Carvalho DAA, Margonari C, Freitas $\mathrm{CR}$, et al. Phlebotominae fauna (Diptera: Psychodidae) in an urban district of Belo Horizonte, Brazil, endemic for visceral leishmaniasis: Characterization of favored locations as determined by spatial analysis. Acta Trop. 2011;117:137-45.

40. Brasil. Ministério da Saúde. Fundação Nacional de Saúde. Manual de controle de roedores. Brasília: Editora do Ministério da Saúde; 2002.

41. Freitas TPT, D'Andrea PS, de Paula DAJ, Nakazato L, Dutra V, Bonvicino CR, et al. Natural Infection of Leishmania (Viannia) braziliensis in Mus musculus Captured in Mato Grosso, Brazil. Vector Borne Zoonotic Dis. 2012;12(1):81-3.

42. Lainson R, Shaw JJ, Silveira FT, Braga RR. American visceral leishmaniasis: on the origin of Leishmania (Leishmania) chagasi. Trans R Soc Trop Med Hyg. 1987;81:517.

43. Humberg RMP, Oshiro ET, Cruz MSP, Ribolla PEM, Alonso DP, Ferreira AMT, et al. Short Report: Leishmania chagasi in Opossums (Didelphis albiventris) in an Urban Area Endemic for Visceral Leishmaniasis, Campo Grande, Mato Grosso do Sul, Brazil. Am J Trop Med Hyg. 2012;87(3):470-2.
44. Gontijo CMF, Silva ES, de Fuccio MB, de Sousa MCA, Pacheco RS, Dias ES, et al. Epidemiological studies of an outbreak of cutaneous leishmaniasis in the Rio Jequitinhonha Valley, Minas Gerais, Brazil. Acta Trop. 2002:81:143-50.

45. Madeira MF, Uchôa CMA, Leal CA, Silva RMM, Duarte R, Magalhães CM, et al. Leishmania (Viannia) braziliensis em cães naturalmente infectados. Rev Soc Bras Med Trop. 2003:36:551-5.

46. Brasil. Ministério da Saúde. Secretaria de Vigilância em Saúde. Departamento de Vigilância Epidemiológica.Manual de vigilância e controle da leishmaniose visceral. Brasília: Editora do Ministério da Saúde; 2006. p. 120.

\section{Submit your next manuscript to BioMed Central and take full advantage of:}

- Convenient online submission

- Thorough peer review

- No space constraints or color figure charges

- Immediate publication on acceptance

- Inclusion in PubMed, CAS, Scopus and Google Scholar

- Research which is freely available for redistribution 